\title{
Educational Endeavour "Computer Science for the Blind" State of the Art and Experiences in Supporting Visually
Handicapped Students
}

\author{
Roland Wagner \\ Bernhard Stöger \\ Klaus Miesenberger \\ Department of Computer Science, Johannes Kepler University, Linz, Austria
}

\begin{abstract}
This report wants to show our experience and line out the state of the art of the Educational Endeavour "Computer Science for the Blind" at the University of Linz. First we will show that supporting visually handicapped at University is a task for Computer Science. After that we will have a look at the social background of a handicap. Special notice we will be given to education and integration. Taking these basic intentions into account we will then focus on the services offered at our university.
\end{abstract}

\section{Introduction}

In 1991 the institute for Computer Science at the University of Linz, Austria, started to support visually handicapped students by offering special services for the integration in normal courses of studies. The chances opened up by new information technology and the necessity to use them in practice in a socially reflected way led to such an engagement at our institute. The goal is to make the integration into different courses for studies - not only computer science - at our university possible. A program for reducing the extra work of visually handicapped was to be established.

\section{The Computer as a Useful Tool and a Starting Point for Integration}

The benefit of information technology for the handicapped, especially for the visually handicapped, is quite obvious. There are many examples which show the practical advantages of these new devices and the new software. Especially this conference shows such possibilities. The computer supports the presentation of the information of (approximately the same) processes for different kinds of accesses (e.g. visually, audible, tactile) at the man-machine interface. The special situation of every user (education, style of working, task, ..., and also the special needs of visually impaired) can be taken into account by this multi-media power. This independence of the output media offers a link for integration into real processes for the visually handicapped. The wide-spread and increasing use of computers shows the possibilities, the necessity and responsibility of supporting the integration.

According to this we want to point out the necessity of a close relation of such an edeavour to computer and/or other technical sciences or practical work: The 
complexity of normal computer systems, the higher complexity of computer systems adapted for visually handicapped with special devices and software, new developments and changes in the way of using the computer (e.g.: Graphical User Interfaces, Networking, Hypertext, Electronic Publishing, ...), the ongoing initial role of the computer as a useful tool for handicapped people - these and other facts show that a close link between integration and theory and practice of information technology is undeniable. The development of new systems for handling several tasks, which can be seen as a general goal of computer science, offers a great chance for handicapped people by opening up a way of access by adapting the man-machine interface. This is and will be a task for computer science and practical work. It is an important experience of our work that high technical knowledge is the basis for supporting the integration of visually handicapped.

\section{The Social Process of Developing a Handicap and the Importance of Education and Integration}

This technical progress must not make us forget the fact that a handicap is a social construct built up by our conventional views and judgements based on handed down social values which are often more prejudices than justified judgements. Like any other social process a handicap has to be treated by looking at the social background first. The handicapped person, the environment, the professionals as well as the "not concerned" have their roles in this play which we learn during socialisation.

We have to be aware of the fact that a physical shortcoming is not the same as a handicap. By concentrating only on the new technical aspects of treating the physical shortcoming as the most conspicuous and noticeable fact of the situation we neglect the social roots of a handicap. Being fascinated by the possibilities for the medical problem we often tend to believe in an "efficient" technical solution for the whole situation and neglect the social circumstances. One of the most important experiences of our work shows that concentrating exclusively on the technical aspects of using the computer can only treat the medical and technical aspects of the physical shortcoming. The enormous amount of possibilities for a technical support extended and still extends the gap between chances of technology and realisation in social programs. These tendencies can lead to situations which confirm the "getthosituation" of the handicapped.

There are also people who work with handicapped persons in practice but are not willing or able to bring the technical chances into use. Being uninformed about or distrustful of new developments some people are not aware of the enormous possibilities of computers. Chances for independence and integration are withheld from the handicapped.

These two extreme tendencies should show what we think is most important for us today: We have to concentrate on social, pedagogical and didactic aspects, when deciding when and how to use the computer for the support of visually handicapped. We have to enable a better use of these possibilities for visually handicapped and try to make people understand and feel that also a visually handicapped person can be a worthy member of our society- not because of using a computer but supported by this tool -. The social context of a handicap invites us to take new technologies as a 
starting point. We have to reflect this social background by offering a program for the use of technical possibilities.

Education plays an important role in this context because of its still growing importance for participation in all kinds of processes within society. Learning has become a task for lifetime. For visually handicapped education is even more important: Managing the normal environment is more complex for the visually handicapped because of the reduced or non-visual approach to the visually arranged world. Faster changes in society increase this complexity. The traditional image of visually handicapped as being "inefficient, dependent, helpless, etc." causes disadvantages in taking part in educational programs as well as the deficit in access to education strengthens the underrating image - a vicious circle and self-fulfilling prophecy -. We are convinced that teaching skills in using the computer can offer a way out of this situation. This knowledge is of high appreciation within our society. The ability to apply computers to independent self-help and to several conventional tasks opens up a chance for more understanding and being accepted as a worthy member in society.

Another basic question is: Why integration? Is it not better and more efficient to treat the special circumstances in special situations? As pointed out above this is only a biased technical and medical view. I want to point out an other important aspect of integration, especially in the field of education: Apart from the general social situation, which make integration a undeniable task anyway, there is also a more social, pedagogical argument: Every social process, group, institution, etc. has its own way of interaction and communication. For participating it is necessary to become familiar with this special behaviour. Such a "secret curriculum" based on special opinions, special vocabulary, ideologies, norms, values, behaviour and so on is built up and transmitted, often without the users being aware of. In their special institutions and situations handicapped people can not learn these special signs of conventional social processes; they behave in their own way which is often strange and unfamiliar. To acquire this "information" it is necessary to have the opportunity of integration. Integration to the highest possible level is indispensable for an adequate technical as well as social qualification.

\section{Program of Support and Accompanying Activities}

The considerations stated above show the background of the endeavour in Linz and reflect on some experience of our work. Although the situation of visually handicapped people in Austria has improved considerably over the past decades, only a small minority among the visually handicapped with outstanding talent and devotion have managed to graduate at university. To improve this situation and following the example of the university of Karlsruhe, Germany, the University of Linz began to open university education to a wider range of visually impaired people in 1991. Beyond that we want to describe our program of support.

It is intended that the endeavour in Linz eliminates to a large extent the enormous amount of extra work which rely on the conventional, visual oriented teaching methods. The basic concept is to support visually handicapped students during their integration in conventional courses of studies and into everyday life at university. 
The university has to impart scientific and practical knowledge in an understandable and usable manner. This task has to be fulfilled by selecting, preparing and presenting suitable contents and examples for all students who have the permission and are willing to study. The access to the official as well as to the "secret curriculum" should help the students to become members of society with academic titles and obligations. In order to make managing this task also possible to visually handicapped students the Institute of Computer Science took the initiative to built up a special service centre with a specific educational, technical as well as scientific task. Let us now have a look at our main activities:

\subsection{Special computer equipment, information services}

According to the students' special needs computer equipment is available at the university campus. Students are supported in two ways:

First of all, they can use adapted computers at several locations at the campus. Up to now four stations are accessible for the students. An additional fully equipped station will be put up this year. Because students take part in different courses we have to pay attention to configure these stations as flexible as possible to be able to move them from one location to the other. All stations are situated at, let me say: "strategic locations for integration" (libraries, programming laboratory, seminar rooms, etc.). If the "strategic location" changes, the station changes its location, too. All "strategic locations" are accessible 24 hours a day.

Secondly, every student has his or her private equipment which is adapted to the special needs of each student. This equipment has to be a portable one. Students can use their equipment at home but they can also rely on all functions of modern word processing when using the prepared digital studying material in the lectures. It enables them also to take notes during a lecture and to give presentations. There is also the possibility to use them at "strategic locations" by connecting them to the network of the University. It is praiseworthy that in Austria public institutions pay the cost of this privat equipment. We want to point out that these possibilities of working at the conventional locations is indispensable for our concept.

Each of these stations can be used as a local PC or can be connected to a local network, which is integrated into the network of the university, which has a gateway to the Internet. The local network facilitates the management of the stations (e.g. online trouble shouting, support of users, installation of software), offers a powerful tool of communication (mailing, access to study material and other information) and makes the supply of special features such as special local information sources (digital newspaper, register, timetable of public transport, information about sportive and cultural events, menus, video text, BBS, CD-Rom, etc.) and access to Internet resources possible. This technical background is the basis for our support.

\subsection{Accompanying program}

Before entering the courses. For a successful start it is necessary to support the first steps at university. To reach this target, we do the following: 
Computer Camp: The idea to organise a computer camp goes back to the fact that visually handicapped children and youngsters should also have the opportunity of support in using the computer in scholl and everyday life. Such a project supports the transfer of knowledge in using the computer. Such projects offer a good chance for the visually impaired children and youngsters to learn to deal with their situation by using the computer, to feel and learn how to play an active role in an integrated groups and thereby to build up a positive sense of identity. The sighted can take up the possibility of interacting with the visually handicapped and can build up a positive image of the visually handicapped, an image with less prejudices. It is important to gain a lot of useful experience for our work with this project. For our work at the university such projects also offer the possibility to support the preparations for a way to university at an early period.

In 1993 we realised the First Integrating Computer Camp. 24 visually handicapped and sighted children and youngsters took part in the camp. In 1994 an international organisation team is working to realise the First International Computer Camp in Austria. Especially for a small country like Austria such connections open the door to a larger international community of visually handicapped. In the following years the idea of a Computer Camp should become a fixed part of our work.

Counselling about studying possibilities and necessities: Counselling youngsters to find an orientation and a decision what they should do after leaving school gets more and more difficult. Therefore different institutions offer a special support in Austria. For visually handicapped their is a special institution offering counselling for entering the labour market. Till now there is no special counselling for visually handicapped people who want to go to university. Therefore we started a counselling program this year (for students in the last two years before leaving school) in co-operation with the Students Counselling Centre of the university and the Austrian representation of students. We have prepared and are still preparing information which is published by different institutions and pass them on in digital form. During personal counselling we concentrate on technical preconditions and knowledge. For students who are interested in studying in Linz we organise information days and orientation units for preparing the first steps at university.

First steps at university: Visually handicapped students who want to join a course of studies in Linz are supported when doing the enormous amount of organisation and bureaucracy at the beginning. We help them with the organisation of a mobility training, finding a room, acquiring the personal equipment, etc. We support the integration into conventional orientation courses offered for all students. We also offer courses in handling the equipment and information resources. To handle this tasks it is necessary to start the preparations as soon as possible. The difficult situation at the beginning makes such an intensive support necessary to form the preconditions for integration. We reduce such efforts step by step to prevent overprotection and to lead the students on a way to independence.

\section{Accompanying the study process.}

Preparing material for study: The most serious and also obvious obstacle for a visually handicapped student is restricted access to written material. Since, as 
mentioned above, these people can work well with a computer, the material (sets of lecture notes, books, folios, contents of the blackboard, exercises, examination questions, etc.) has to be presented in digital form. We employ special tutors to do this work. These tutors are senior students with profound knowledge in the field of the lecture which they are allocated to. The tutors are allocated to a lecture and not to the student or to us. Obviously their work is strongly dependent on the form in which the particular material is presented:

a) The material is already available in digital form. In such a case the tutor's task is to reformat, to number and to structure the material with a wide-spread word processing program. The tutor should work out a structure which makes a general overview, a better and faster orientation and moving through the text possible.

For blind students this seems to be the only possible way, as presenting material in Braille needs a high a amount of paper. Only the most important parts of a material are printed in Braille. The students can also use a Braille printer to make outputs for themselves.

The digital information also has striking advantages for partially sighted students, because of the possibility of producing printed outputs which are adapted to their special needs and to use screen enlarging software or speech output for an alternating, not tiring access with the computer.

Graphics also have to be embedded into the text. Tutors have to produce simplified tactile graphics with additional explanations for the blind students. All graphics are numbered and collected in a map; references to the numbered graphics are made in the text. For the partially sighted students the graphics also have to be adapted and integrated in the digital as well in the printed version.

It is an important experience that two or often more versions of every material have to be made to cope with the special needs of the students. Therefore the digital form of a material is indispensable. We also want to point out the importance of using a wide-spread and well known software for presenting the material in order to facilitate co-operation and integration.

Our biggest problem in this context is the access to the material in digital form to facilitate our work. Theoretically, every person who prepares printed material uses or is able to use a computer for this work at out university and therefore a digital source exists. In practice, however, we often fail to get such a digital original since the authors or publishers are often not willing to pass it on. We hope that this access will be facilitated in future. Extensive public relations work in- and outside the university has to be done to make authors, publishers and also the public become aware of this disadvantage. As a first step one publishing house is willing to hand over all scientific books in digital form if one exists and the author consents.

New developments in the field of publishing (e.g. hypertext systems) and teaching (e.g. Computer aided lectures) offer a great chance for an access to the material in digital form but there are also tendencies to a more graphic oriented presentation which confronts us with new tasks. We make several scientific efforts to test such new systems which are used at the university due to the possibility of an access for visually handicapped students. 
b) The material is presented in printed form: For partially sighted students sometimes an enlarged copy of print material is suitable. Mostly we produce a digital version which is of advantage for both the partially sighted and the blind students. The tutors use a high-resolving scanner together with teachable OCR software to convert the material into digital form. Then the process can continue as described in a). Like in a) there is the problem of getting the permission for preparing a digital version of the material.

c) The material is presented in hand-written form: There is no other way but typing the whole hand-written text and then to proceed as in a).

d) The material contains mathematical symbols: Mathematical symbols represent an additional difficulty. There is the need for an ASCII representation of mathematical formulae. We have decided to use the source code of the mathematical word processing program TEX, since this is well known to many people working in the fields of mathematics, physics, computer science etc. Students able to read TEX source enjoy the additional advantage that whenever they need to produce mathematical texts in printed form, then the ideal tool for this task is at their hand. While the TEX source itself presents mathematics to a totally blind student in a readable form, partially sighted students cannot be expected to read formulae in this notation. However, since the TEX package contains a previewer that lets "TEXed" formulae appear on the screen as they would appear in a book, using TEX satisfies both groups of clients. If we get material in TEX, the tutors have to "simplify" the source (not the contents) by deleting unnecessary layout instructions. Printed as well as hand-written material has to be brought into TEX by hand.

In addition we make a scientific effort to facilitate the production of suitable TEX sources in co-operation with the Research Institute for Symbolic Computing (RISC) at our university.

The material should be available at our network BEFORE the lectures. The visually handicapped student should have the opportunity to use the material in the lecture. It has to be pointed out that the success of the support of a lecture highly depends on the will of the lecturer. Problems, which are often said to be a mistake of our work, are caused by the style of education (no material, no preparation of the lectures, etc.) which makes our support difficult. Because of the necessity of a change in their educational style the lecturers tend to prefer "extra" situations for the visually handicapped, which seem to be more "efficient" in the sense pointed out above. One of the most important points in our work is making people understand the concept of integration and their own responsibility. Unfortunately we cannot offer a complete solution to all problems in access to material. To provide support in difficult situations our tutors hold repetition sessions in which they answer questions of the students resulting from their inability to follow the presentation. It is important to say that this does not mean that we reduce the requirements for studying or that we are an excuse for the lecturers. This is a necessary task for an equal access and no overprotection. 
Counselling and care: The students are obliged to organise their lectures with the lecturers themselves. If problems occur we offer support. To facilitate this process in general we organise meetings and visits at the lecturers to give them a better understanding of our goals. The students also have to arrange their conditions of examination. In general they have more time or can take the exam in verbal form. If necessary we invigilate the exam because of its longer duration. To support the selforganisation of the lectures and the integration into them, a special "social-skilltraining" is organised. The students can participate voluntarily in such courses which are held by professional psychologists. We are not responsible for the organisation of their studies but it is necessary to support them in case of questions related to studying or personal problems based on the social background and social circumstances of handicap.

First steps into working life. The over all goal of the endeavour is the integration into working life. To make this transition easier we build up contacts to industrial companies, to civil services as well as to job centres, visit different institutions to present how visually handicapped people fulfil their task and organise periods of practical training.

The endeavour is accompanied by an interdisciplinary research program and a supervision system for the stuff. We are also in close co-operation with the universities of Karlsruhe and Dresden which offer similar programs. The exchange of experience and co-operation in several fields (e.g. exchange of students and tutors) should be strengthened.

\section{Conclusion}

The necessity of such an endeavour at university was expressed best by one of our students. He said that the mere fact that there is an institution which takes care of the special situation of the visually handicapped students facilitates studying as lecturers and the other stuff gets to know that they have to be aware of their responsibility towards these people. We have to say that "equal access" can and does not mean "equal efforts". The students have to care for themselves, a fact which may make higher efforts necessary. Integration should also look for conditions, which avoid overprotection. The visually handicapped should have the opportunity to learn to handle their situation, not only for managing their job at university but also in everyday life. Like all the other students they should have the opportunity to learn their lesson in self-organisation and independence.

Ten students, four of them are blind and six are partially sighted, use the support of our endeavour. They are studying Computer Science, Law and Business. Another crucial feature of our university is that people with no university qualifications can obtained the right to study by attending a year's foundation course. We also support this course. However, we are sure that it will help many blind and visually impaired people who had, until now, no chance of obtaining a university qualification. In future we will try to build up the organisational framework to be able to support all courses of studies held in Linz. 